\title{
Commentary: Expanded polytetrafluoroethylene: Making the reoperative experience easier or making more reoperations?
}

\author{
Francis D. Pagani, MD, PhD
}

\author{
From the Department of Cardiac Surgery, University of Michigan, Ann Arbor, Mich. \\ Disclosures: Author has nothing to disclose with regard to commercial support. \\ Received for publication Nov 2, 2018; accepted for publication Nov 2, 2018; available ahead of print Nov 30, \\ 2018. \\ Address for reprints: Francis D. Pagani, MD, PhD, Otto Gago, MD Endowed Professor of Cardiac Surgery, Uni- \\ versity of Michigan, 5161 Cardiovascular Center, 1500 East Medical Center Drive, Ann Arbor, MI 48109 \\ (E-mail: fpagani@umich.edu). \\ J Thorac Cardiovasc Surg 2019;157:e263 \\ $0022-5223 / \$ 36.00$ \\ Copyright (C) 2018 by The American Association for Thoracic Surgery \\ https://doi.org/10.1016/j.jtcvs.2018.11.007
}

Durable left ventricular assist device (LVAD) therapy has become the principal treatment for patients with advanced heart failure (American Heart Association, Stage D) who have significant symptom burden despite optimal medical management. LVADs are intended to support patients for extended periods of time as a bridge to heart transplantation or for destination therapy, but frequently require explantation for heart transplantation, cardiac recovery, or management of device complications such as pump thrombosis, device malfunction, or infection. The reoperation and explant of a durable LVAD can be a formidable operation, particularly in the setting of multiple prior operations or in the setting of hemodynamic instability from device malfunction. To facilitate reoperation in these settings, many surgeons have incorporated protective barriers such as expanded polytetrafluoroethylene (ePTFE) membrane at the time of the initial implant to reconstruct the pericardium or wrap the device to prevent fibrous adhesions and facilitate reoperation and device removal. ${ }^{1-3}$ Despite the major advantages of pericardial substitutes to facilitate reoperation, their use has been associated with infections or inflammatory processes contributing to seroma formation.

In this issue of the Journal, Jackson and colleagues ${ }^{4}$ present an interesting complication of the use of ePTFE membrane in the setting of LVAD implantation where the outflow graft of the LVAD was wrapped with ePTFE membrane. These authors identified late-onset (average 3.4 years) outflow graft obstruction of the LVAD arising from external compression of the outflow graft thought to arise from plasma and serum leak from the outflow graft that was trapped in the virtual space between the ePTFE and the outflow graft. In each case, the outflow graft obstruction was identified with computed tomography of infection.

\section{References} 2001;19:302-6. sion. 2016;31:436-7.

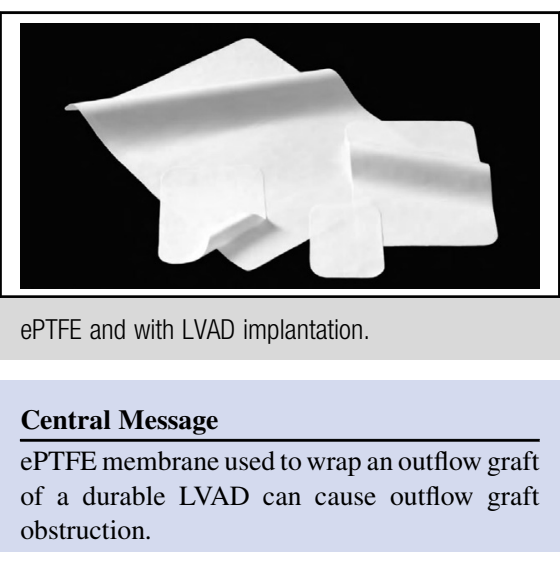

See Article page e259.

scan with angiography and required reoperation and replacement of the outflow graft to resolve the obstruction. In this case, Jackson and colleagues ${ }^{4}$ have suggested that fenestration of the ePTFE wrap may avoid this complication by preventing entrapment of the plasma and serum leaking from the outflow graft. Other approaches may be to simply limit the amount of ePTFE used or apply the ePTFE anteriorly in the pericardial space without wrapping, or avoid its use. Purists may argue that addition of these barriers adds to the degree of fibrous formation and to the risk

Although unusual, this complication speaks to the unintended consequences of a simple technique thought to facilitate the operative procedure and highlights the importance of case reports to inform us of these consequences and how to modify our approach.

1. Holman WL, Bourge RC, Zorn GL, Brantley LH, Kirklin JK. Use of expanded polytetrafluoroethylene pericardial substitute with left ventricular assist devices. Ann Thorac Surg. 1993;55:181-3.

2. Leprince P, Rahmati M, Bonnet N, Bors V, Rama A, Léger P, et al. Expanded polytetrafluoroethylene membranes to wrap surfaces of circulatory support devices in patients undergoing bridge to heart transplantation. Eur J Cardiothorac Surg.

3. Mohite PN, Sabashnikov A, Popov AF, Fatullayev J, Simon AR. Use of PTFE patch for pericardial closure after minimal invasive LVAD implantation. Perfu-

4. Jackson GR, Brand T, Katz JN, Ikonomidis JS. Left ventricular assist device failure due to outflow graft compression by thrombofibrotic exudate. J Thorac Cardiovasc Surg. 2019;157:e259-61. 